\title{
A educação ambiental em ambiente escolar através da prática de vermicompostagem como forma de tratamento para os resíduos sólidos orgânicos
}

Diante do atual cenário em que estamos inseridos, com a geração de grande quantidade de resíduos sólidos, manejo inadequado e escassez de informações, ações de educação ambiental se faz de extrema necessidade a fim de promover a conscientização ambiental e mudanças comportamentais na sociedade. Neste sentido, o objetivo do trabalho foi desenvolver ações de Educação Ambiental (EA) com os alunos de uma escola pública localizada no município de Pelotas/RS, Brasil, através do ensino das formas de gerenciamento e tratamento dos resíduos, com enfoque no tratamento dos resíduos sólidos orgânicos através da prática sustentável de vermicompostagem. Foram desenvolvidas atividades teóricas e práticas com os alunos de uma turma do 60 ano, e aplicado um questionário inicial e final visando avaliar os conhecimentos adquiridos. Com a aplicação do projeto na escola, os alunos aprenderam a respeito das formas corretas de segregação, acondicionamento, coleta e destinação dos resíduos sólidos. Os alunos aprenderam a montar e manejar uma vermicomposteira em um sistema de pequena escala, o que possibilita a execução da técnica de vermicompostagem em locais com reduzida disponibilidade de espaço. A maioria dos alunos mostrou entendimento em relação aos resíduos sólidos e da importância do seu correto manejo, foram bastante participativos principalmente nas atividades práticas, e demonstraram entendimento e interesse em montar uma vermicomposteira em suas residências.

\section{Environmental education in school environment through the vermicomposting practice as a form of treatment for organic solid \\ waste}

\begin{abstract}
Against the current scenario where we are inserted, with large amounts of solid waste being produced, inappropriate handling and lack of information, environmental education actions are crucial in order to promote environmental awareness and behavioral changes in our society. In this sense, the aim of this work was to develop some Environmental Education (EE) actions with students from a public school located in the city of Pelotas/RS, Brazil, by teaching ways of waste management and treatment, with a focus on organic solid waste treatment, through the sustainable practice of vermicomposting. Theoretical and practical activities were developed with the students of a 6th grade class, and an initial and final questionnaire was applied in order to assess the acquired knowledge. With the application of this project at school, students could learn about the correct ways of separating, packaging, collecting and the destination of solid waste. The students learned how to assemble and handle a vermicomposter in a small-scale system, which makes it possible to perform the vermicomposting technique in places with reduced space availability. Most of the students showed understanding towards the solid waste and the importance of its correct handling. They were very participative, mainly in practical activities, and showed understanding and interest in setting up a vermicomposter in their houses.
\end{abstract}

Keywords: Environmental education; Schools; Management; Solid waste; Vermicomposting.

Topic: Educação Ambiental

Reviewed anonymously in the process of blind peer.

Vanessa Sacramento Cerqueira (iD)

Universidade Federal de Pelotas, Brasil

http://lattes.cnpq.br/5269420717974016

http://orcid.org/0000-0003-2604-7846

vanescerqueira@yahoo.com.br

Helena Jung Adamoli

Universidade Federal de Pelotas, Brasil

http://lattes.cnpq.br/9507108805624184

helenaadamoli@hotmail.com

Cláudia Fernanda Lemons e Silva (iD)

Universidade Federal de Pelotas, Brasil

http://lattes.cnpq.br/9507108805624184

http://orcid.org/0000-0001-7187-7000

lemonsclau@gmail.com
Received: 03/04/2021

Approved: 26/04/2021
Marcelo Ferreira Pedra Junior

Universidade Federal de Pelotas, Brasil

http://lattes.cnpq.br/3926306100870001

marcelo fpedra@hotmail.com
Referencing this:

CERQUEIRA, V. S.; ADAMOLI, H. J.; SILVA, C. F. L.; PEDRA JUNIOR, M. F.. A educação ambiental em ambiente escolar através da prática de vermicompostagem como forma de tratamento para os resíduos sólidos orgânicos. Revista Ibero Americana de Ciências Ambientais, v.12, n.4, p.754-766, 2021. DOI: http://doi.org/10.6008/CBPC2179$\underline{6858.2021 .004 .0057}$ 
A educação ambiental em ambiente escolar através da prática de vermicompostagem como forma de tratamento para os resíduos sólidos orgânicos

\section{INTRODUÇÃO}

A adoção de práticas ambientais sustentáveis é uma questão emergente e de extrema importância visando a minimização de impactos ambientais adversos. No Brasil, nos últimos anos, tem sido evidenciado aumento considerável na geração de resíduos sólidos urbanos passando de 67 milhões de toneladas ao ano em 2010 para 79 milhões de toneladas por ano em 2019 (ABRELPE, 2020). Mundialmente, a média de resíduos gerados por pessoa por dia é de $0,74 \mathrm{Kg}$, e a estimativa é que a taxa de geração mundial anual de resíduos sólidos urbanos aumente dos atuais 2,01 bilhões de toneladas para 3,4 bilhões de toneladas até o ano de 2050 (KAZA et al., 2018; LIAO et al., 2019).

O crescimento populacional, o desenvolvimento econômico, aumento na taxa de produção pautada pela obsolescência programada dos produtos e mudança nos padrões de consumo baseados no consumo excessivo e supérfluo, estão entre os fatores que têm contribuído com o aumento significativo da geração de resíduos sólidos (IQBAL et al., 2020; JACOBI et al., 2011). A elevada taxa de geração e a falta de gerenciamento ou gerenciamento inadequado dos resíduos sólidos podem resultar em sérios problemas relacionados ao meio ambiente e à saúde pública, devido a possibilidade de contaminação de ambientes hídricos, solos, poluição do ar, contribuição ao aumento do efeito estufa e proliferação de vetores transmissores de doenças (AYILARA et al., 2020; ALAM et al., 2013).

Neste sentido, se torna cada vez mais evidente que a adoção de padrões sustentáveis de produção e consumo e o gerenciamento adequado dos resíduos sólidos, podem minimizar significativamente os impactos negativos (JACOBI et al., 2011). No Brasil, no ano de 2010, foi instituída a Política Nacional de Resíduos Sólidos (PNRS), Lei Federal n.12.305, que dispõe sobre a gestão integrada e ao gerenciamento de resíduos sólidos, e traz responsabilidades aos geradores de resíduos e ao poder público. Dentre os objetivos desta lei, destaca-se o estímulo à adoção de padrões sustentáveis de produção e consumo; a adoção de tecnologias limpas; incentivo à reciclagem; e adoção da seguinte ordem de prioridade na gestão e gerenciamento de resíduos sólidos: não geração, redução, reutilização, reciclagem e tratamento dos resíduos sólidos, bem como a disposição final ambientalmente adequada dos rejeitos (PNRS, 2010), de modo a causar o mínimo possível de impacto negativo no meio ambiente.

Um dos importantes instrumentos da PNRS é a Educação Ambiental (EA) que, conforme citado por Arnaldo et al. (2018), consiste em uma prática que proporciona aos indivíduos condições cognitivas para que, por meio de ações coletivas, promovam mudanças na ordem estrutural de nossa sociedade e nas consequentes relações com a natureza, buscando superar o modelo de sociedade atual.

A EA é de fundamental importância para a efetiva transformação social e alcance da sustentabilidade ambiental através de ações que promovam a sensibilização de indivíduos críticos e conscientes de seu papel na sociedade, o repensar de valores e atitudes cotidianas, a construção de saberes, a difusão de conhecimentos, o despertar do sentimento de pertencimento no mundo em que vivem assim como a construção de novos valores e relações com o meio ambiente visando a melhoria da qualidade de vida para todos os seres (ARNALDO et al., 2018; MENDONÇA et al., 2020). 
A educação ambiental em ambiente escolar através da prática de vermicompostagem como forma de tratamento para os resíduos sólidos

A EA em escolas se torna cada vez mais essencial, uma vez que as crianças, desde cedo, podem compreender a importância da necessidade de preservar o meio ambiente, do uso racional dos recursos naturais e do equilíbrio entre homem e a natureza, se tornando assim adultos conscientes e preocupados com o meio ambiente (MEDEIROS et al., 2011; MENDONÇA et al., 2020). Além disso, é possível que as crianças atuem como multiplicadoras dos conhecimentos adquiridos na escola, contribuindo para a conscientização e mudança de comportamento de outras pessoas, como seus familiares, vizinhos e comunidade (RADA et al., 2016; MEDEIROS et al., 2011). É importante que a EA seja discutida no ambiente educacional, não apenas em momentos específicos, mas de forma contínua, devendo ser desenvolvida de forma transversal e interdisciplinar, estando inserida em diferentes disciplinas (ALCÂNTARA et al., 2016; ALENCAR et al., 2020; MARQUES et al., 2018; MENDONÇA et al., 2020).

A PNRS também incentiva a implementação da tecnologia de compostagem para os resíduos orgânicos, que em sua maioria têm sido enviados a formas de disposição final junto aos rejeitos (ZAGO et al., 2019). A compostagem é um processo aeróbico de degradação da matéria orgânica mediado por microrganismos que gera como produto final o composto orgânico (LOUREIRO et al., 2007). Uma variante desta técnica é a vermicompostagem, que consiste em um processo muito eficaz de transformação da matéria orgânica realizada através da ação conjunta de minhocas e microrganismos originando como produto final o vermicomposto, o qual é muito útil para a fertilidade do solo e o desenvolvimento de plantas (LOUREIRO et al., 2007; PATHMA et al., 2012).

A aplicação de técnicas de compostagem e vermicompostagem é extremamente interessante pois, além de dar um destino ecologicamente correto para os resíduos provenientes de restos vegetais e animais, traz como vantagem a geração de produtos de mais alto valor agregado que servem para a adubação orgânica, sendo utilizados para o cultivo de plantas e produção de alimentos (AQUINO et al., 2005; LOUREIRO et al., 2007; WANI et al., 2013).

Neste sentido, realizar ações educativas voltadas a temática dos resíduos sólidos, através do ensino do correto gerenciamento e formas de realizar a reciclagem dos resíduos, em especial dos resíduos sólidos orgânicos através da vermicompostagem em sistemas de pequena escala, se faz de extrema necessidade visando despertar nos alunos a consciência e responsabilidade ambiental e o interesse em segregar e reciclar os resíduos orgânicos gerados em suas residências e na escola de forma fácil, simples e de baixo custo.

Assim, este trabalho teve como objetivo desenvolver ações de educação ambiental, com os alunos do 60 ano de uma escola pública de Pelotas/RS, com ênfase no tratamento dos resíduos sólidos orgânicos através da prática sustentável de vermicompostagem.

\section{METODOLOGIA}

O projeto foi desenvolvido em uma escola pública da rede municipal, localizada no bairro Porto na cidade de Pelotas/RS, Brasil, no ano de 2019. O público alvo foi os alunos do 6o ano do ensino fundamental. Visando avaliar o conhecimento prévio dos alunos acerca da temática resíduos sólidos, bem como os 
A educação ambiental em ambiente escolar através da prática de vermicompostagem como forma de tratamento para os resíduos sólidos orgânicos

CERQUEIRA, V. S.; ADAMOLI, H. J.; SILVA, C. F. L.; PEDRA JUNIOR, M. F.

conhecimentos adquiridos com o desenvolvimento do projeto, foi aplicado o mesmo modelo de questionário, de forma individualizada, antes e após as atividades, respectivamente, contendo 14 perguntas algumas dissertativas e outras de múltipla escolha.

Foram realizadas oficinas teóricas e práticas de forma intercaladas. Nas atividades teóricas foram transmitidos conhecimentos sobre conceitos de resíduos e rejeitos, problemática ambiental causada pelo manejo incorreto dos resíduos, classificação, geração, formas corretas de segregação, acondicionamento, coleta e destinação dos resíduos sólidos, disposição final de rejeitos, logística reversa, formas de minimização da geração dos resíduos, formas de aproveitamento com enfoque na vermicompostagem como forma de tratamento dos resíduos sólidos orgânicos. Foram abordados conceitos de vermicompostagem, funcionamento do processo, montagem e manejo de uma vermicomposteira e usos do vermicomposto.

A primeira atividade prática consistiu em uma dinâmica em que os alunos deveriam segregar e acondicionar de forma correta diferentes resíduos sólidos e rejeitos (Tabela 1) em coletores com diferentes cores de acordo com o estabelecido na Resolução do Conselho Nacional do Meio Ambiente (Conama) n.275 de 2001. Os alunos foram distribuídos em grupos com 4 componentes cada e todos os grupos receberam os mesmos resíduos os quais foram disponibilizados pelo grupo do projeto.

Tabela 1: Resíduos disponibilizados para realização da atividade prática de segregação e acondicionamento dos resíduos

Resíduos

Adesivo

Bateria de celular

Casca de banana

Casca de ovo

Casca de mamão

Erva mate

Garrafas Pet

Latinha de refrigerante

Lacre da latinha de refrigerante

Papel de caderno

\author{
Embalagem de bala \\ Embalagem de chocolate \\ Embalagem de salgadinho \\ Rótulo da embalagem de refrigerante \\ Fita adesiva transparente amassada \\ Pilhas \\ Guardanapo \\ Guardanapo sujo \\ Filtro de café usado
}

A segunda atividade prática consistiu em desenvolver brinquedos a partir de resíduos recicláveis das categorias plástico e papel. O grupo do projeto disponibilizou três modelos de brinquedos a partir de materiais recicláveis para que eles escolhessem qual gostariam de fazer. 0 grupo disponibilizou todo o material necessário para a elaboração dos brinquedos. A prática teve por intuito incentivar os alunos à adoção de práticas de reciclagem.

Outra atividade aplicada foi um jogo de perguntas e respostas, Quiz, onde os alunos, distribuídos em grupos, deveriam responder à diferentes questões relacionadas aos resíduos. Foram entregues placas de 'sim' e 'não' para os alunos.

A fim de demonstrar formas de aproveitamento dos resíduos orgânicos foi ensinado aos alunos como realizar a prática de vermicompostagem e como montar uma vermicomposteira em residências. Para isto, inicialmente foi demostrada a forma de execução pelo grupo do projeto a todos os alunos, e posteriormente foi feita toda a montagem e execução da vermicomposteira pelos próprios alunos da escola. Foi disponibilizado todo o material necessário para a prática. A vermicomposteira permaneceu na escola para 
A educação ambiental em ambiente escolar através da prática de vermicompostagem como forma de tratamento para os resíduos sólidos

que os alunos acompanhassem todo o processo de transformação dos resíduos em composto orgânico. Semanalmente, o grupo do projeto visitou a escola para manutenção das vermicomposteiras.

\section{RESULTADOS E DISCUSSÃO}

Este projeto vem sendo desenvolvido desde o ano de 2015, quando foi criado e implementado como projeto de extensão, pelo grupo de pesquisa e extensão coordenado pela autora deste trabalho na Universidade Federal de Pelotas. Desde então, todos os anos vem sendo aplicado o projeto em diferentes escolas no município de Pelotas/RS.

O projeto tem como intuito ensinar e incentivar a prática de vermicompostagem aos alunos das escolas, como alternativa sustentável para o tratamento dos resíduos orgânicos gerados, seja na escola ou nas suas residências. É também transmitido conhecimentos voltados ao gerenciamento dos resíduos sólidos em sua totalidade para que os alunos possam compreender de melhor forma todas as etapas envolvidas no processo e que é de fundamental importância para o aproveitamento da fração orgânica presente nos resíduos sólidos urbanos através da vermicompostagem.

O presente trabalho foi desenvolvido com uma turma do $6^{\circ}$ ano, composta por $38 \%$ de alunos do sexo feminino e $62 \%$ do sexo masculino, com idade entre 11 e 14 anos. Durante as atividades teóricas, a maioria dos alunos se mostrou interessada nas explicações, sendo que alguns foram bastante participativos citando exemplos sobre os assuntos abordados e sugerindo soluções para a gestão dos resíduos.

A fim de tornar o conhecimento mais aprofundado e promover a fixação dos conhecimentos adquiridos, atividades práticas foram aplicadas de forma intercalada às atividades teóricas. Foi possível observar que os alunos se mostraram bastante entusiasmados durante a realização das atividades práticas e também mais concentrados. A aplicação de atividades lúdicas torna o processo de ensino-aprendizagem escolar mais intenso que nas atividades tradicionais pois estimulam o processo cognitivo das crianças (CEMBRANEL et al., 2019). É importante que sejam desenvolvidas atividades práticas, além das teóricas, e que sejam relacionadas às questões do cotidiano, no intuito de que as crianças possam praticar ações para a preservação do meio ambiente (MEDEIROS et al., 2011).

A primeira atividade prática teve por objetivo abordar a forma correta de segregação dos resíduos. Após ensinar aos alunos as formas de segregação, de acordo com a tipologia do resíduo, acondicionamento e coleta dos resíduos, a fim de dar ênfase a estas explicações, foi realizada uma dinâmica, conforme mostrado na Figura 1.

Para cada grupo, foram disponibilizados recipientes com diferentes cores (azul, amarelo, verde, vermelho, laranja, cinza e marrom), de acordo com a resolução do CONAMA n.275 que estabelece o código de cores para os diferentes tipos de resíduos, a ser adotado na identificação de coletores e transportadores, bem como nas campanhas informativas para a coleta seletiva (CONAMA, 2001). Nesta prática, dos três grupos participantes, apenas um apresentou bom desempenho nas atividades, com menor número de erros, tendo errado apenas o filtro de café usado e o plástico da embalagem de chocolate que colocaram em 
A educação ambiental em ambiente escolar através da prática de vermicompostagem como forma de tratamento para os resíduos sólidos orgânicos

coletores errados. Os outros grupos cometeram diversos erros, tais como, papel no coletor de cor laranja, os resíduos perigosos no de cor azul e plástico no coletor de cor verde.

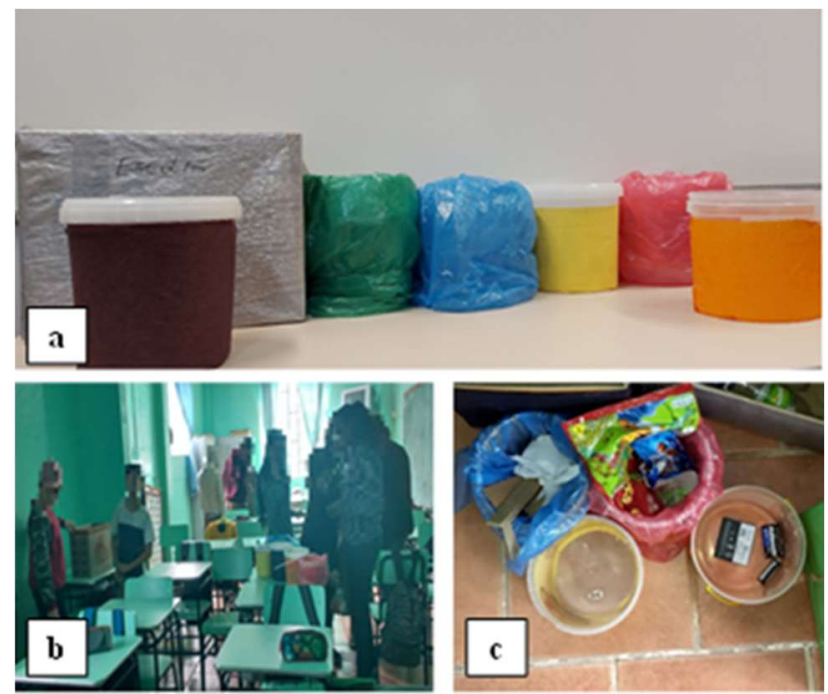

Figura 1: (a) Coletores utilizados na prática de segregação; (b) Alunos participando da dinâmica de descarte de resíduos; (c) Resíduos segregados.

Ter conhecimento de como fazer a separação dos resíduos sólidos de forma correta é crucial para o sucesso das etapas envolvidas no gerenciamento dos resíduos. É de extrema importância realizar a correta segregação dos resíduos pois possibilita o aproveitamento das frações de resíduos e diminui a quantidade de rejeitos gerados, os quais são enviados para disposição final em aterros sanitários. A prática de separação de resíduos diminui os impactos negativos gerados ao meio ambiente, possibilitando o aproveitamento das principais frações de resíduos gerados nas escolas e residências, como os recicláveis e orgânicos, por exemplo, através da reciclagem e vermicompostagem, respectivamente.

Tendo por intuito mostrar aos alunos opções de aproveitamento dos resíduos recicláveis, foi aplicada a segunda atividade prática que consistiu na confecção de brinquedos utilizando resíduos como garrafas pet, tampinhas, papel, entre outros. Foi disponibilizado aos alunos três opções para a confecção de brinquedos recicláveis, os modelos minion, cofre de porquinho e avião (Figura 2). As meninas, na sua totalidade, optaram por fazer o cofre de porquinho. Já os meninos escolheram fazer o avião, com exceção de um aluno que optou pelo modelo do minion.

Nesta atividade, os alunos se mostraram bastante empolgados, participativos e colaborativos, cada um confeccionando o seu brinquedo, mas se disponibilizando a ajudar o colega quando era necessário. Atividades como esta são importantes de serem trabalhadas com crianças, pois incentiva a reciclar os resíduos e a não descartar pensando que estes não terão mais utilidade. Além disto, faz com que eles percebam que a reciclagem é uma forma de não contaminar o meio ambiente, e que quando os resíduos são enviados para a reciclagem ajuda no sustento dos trabalhadores de cooperativas de reciclagem. Com isto, gera impactos positivos no meio ambiente e na vida dos trabalhadores desta área.

Dentre os principais constituintes dos resíduos sólidos urbanos cita-se o plástico. Medidas imediatas são necessárias para evitar o descarte de resíduos plásticos, incentivando a atuação da população de modo 
a reduzir os resíduos e de modo a fazer segregação na fonte geradora. Incentivar e ensinar a população, principalmente os jovens, é uma estratégia positiva para aquisição de conhecimentos e comportamentos em relação às questões ambientais para reduzir o desperdício de plástico (SO et al., 2019).

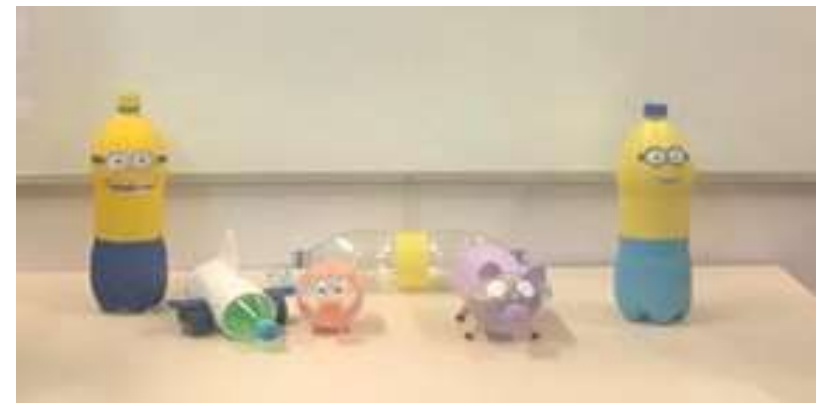

Figura 2: Brinquedos recicláveis confeccionados pelos alunos

Visando a adoção de uma forma sustentável de aproveitamento da fração orgânica gerada nas escolas e nos domicílios foi ensinado aos alunos da escola a técnica de vermicompostagem, envolvendo a montagem de uma vermicomposteira em pequena escala, conforme mostrado nas Figuras 3 e 4 . Foi também explicado características das minhocas e quais são as comumente utilizadas na vermicompostagem. Foi disponibilizado a eles todo material necessário à montagem da vermicomposteira (maravalha, resíduos orgânicos e as minhocas da espécie Eisenia andrei). Após demonstração pelo grupo do projeto, os alunos da escola realizaram todo o processo, onde quase a totalidade deles participaram diretamente da montagem..
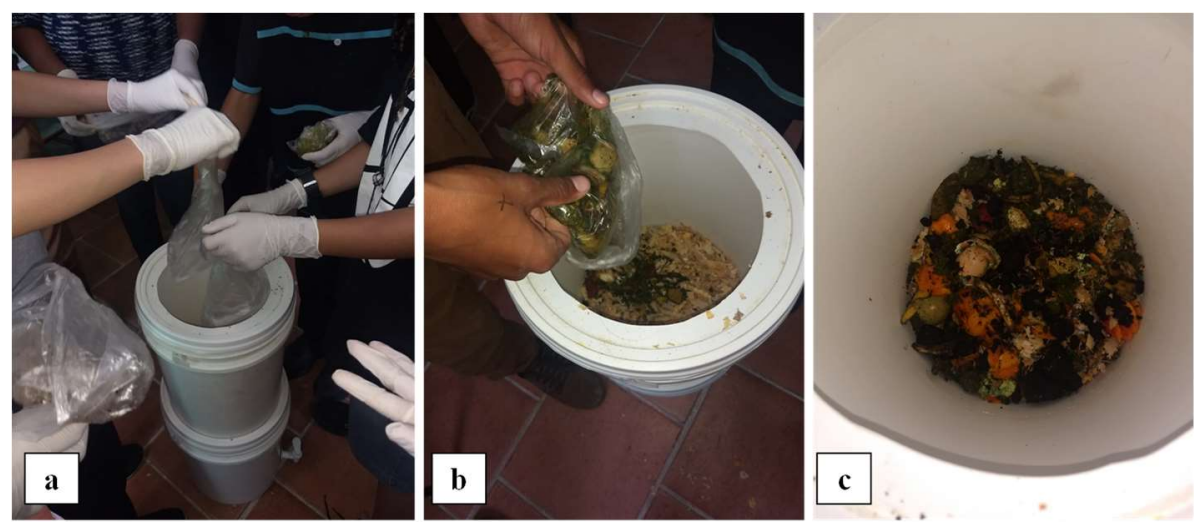

Figura 3: (a) Alunos adicionando maravalha; (b) Alunos adicionando os resíduos orgânicos; (c) Resíduos e maravalha adicionados no sistema de baldes.

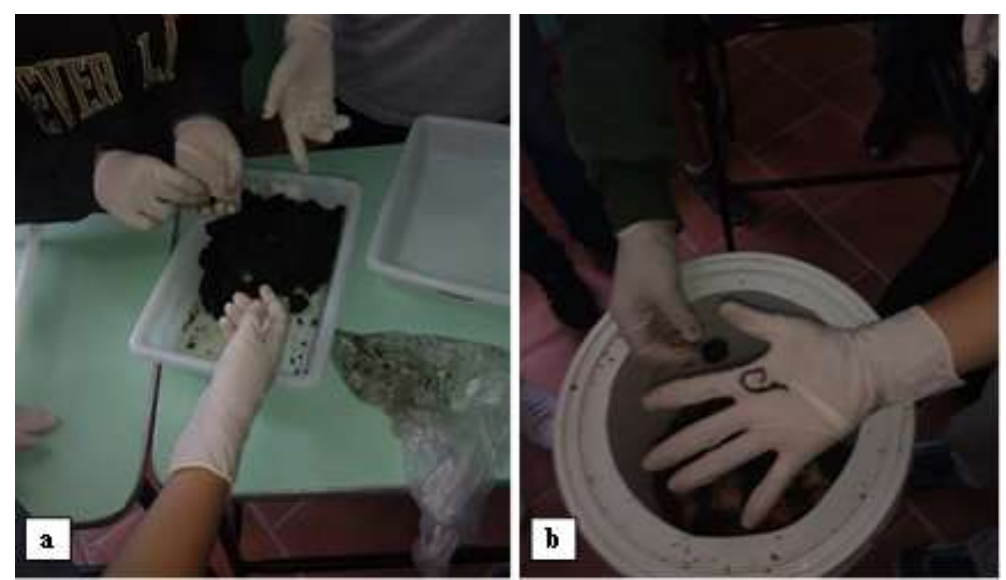

Figura 4: (a) Alunos selecionando as minhocas; (b) Alunos adicionando as minhocas ao sistema de baldes. 
A educação ambiental em ambiente escolar através da prática de vermicompostagem como forma de tratamento para os resíduos sólidos

A educação ambiental por meio da vermicompostagem mostrou ser uma importante ferramenta pedagógica no processo de ensino e aprendizagem, onde os alunos se mostraram extremamente interessados e participativos, sendo esta atividade a que os alunos mostraram maior empolgação para a sua execução. A técnica de vermicompostagem é extremamente interessante para o sustentável tratamento dos resíduos sólidos orgânicos gerados diariamente. Esta técnica é de grande relevância, pois além de dar destino correto aos resíduos, minimizando o volume enviado a aterros sanitários ou descarte em locais inadequados, também traz como benefício a geração do vermicomposto.

O material compostado aumenta a produtividade agrícola e o conteúdo de matéria orgânica do solo, sendo também benéfico para o controle de doenças de plantas, controle de ervas daninhas, controle da erosão e redução de riscos ambientais associados ao uso de fertilizantes sintéticos. Os fertilizantes químicos causam poluição ambiental, destruição da camada de ozônio, contribuem para o efeito estufa, doenças humanas, entre outros (AYILARA et al., 2020).

A vermicompostagem é muito interessante de ser realizada tanto em residências como na própria escola podendo o vermicomposto ser aplicado em hortas e jardins. Nas escolas os alunos, professores e funcionários podem montar hortas e jardins para que todos cuidem e façam a sua manutenção. Além de despertar a consciência ambiental também desperta o sentimento de pertencimento neste processo.

No caso de escolas que servem refeições, como na escola onde foi realizado o projeto, a adoção da vermicompostagem e a construção de hortas pela comunidade escolar se faz extremamente interessante visto que, possibilita tratar os resíduos gerados no preparo das refeições bem como àqueles gerados em outros momentos, e também o uso do vermicomposto para a produção de seus próprios alimentos, como hortaliças, trazendo diversos impactos positivos no ambiente escolar.

Tanto em residências como nas escolas, o vermicomposto também pode ser utilizado para projetos de paisagismo. O uso do sistema de baldes se destaca por possibilitar a realização da técnica de vermicompostagem em espaços com reduzida disponibilidade de espaço como o caso de algumas residências, além de ser de fácil manejo e de baixo custo.

No jogo de perguntas e respostas, quiz, foram feitas dez perguntas envolvendo assuntos relativos a descarte correto, responsabilidades, logística reversa, pontos de entrega voluntária (PEV's) e compostagem. Os resultados obtidos foram muito satisfatórios, sendo que houveram erros em apenas duas perguntas, que envolviam logística reversa e compostagem.

Questionários foram aplicados aos alunos a fim de avaliar os conhecimentos adquiridos com a execução do projeto na escola. Conforme se observa na Figura 5, a maioria dos alunos, após as explicações feitas pela equipe do projeto, compreendeu os conceitos sobre resíduos sólidos e a importância da segregação. Observou-se que $54 \%$ dos alunos fazem a separação em casa, entretanto, os alunos que ainda não fazem responderam, através de pergunta feita no questionário, que gostariam de fazer. Com isto, percebe-se que as atividades desenvolvidas em escolas são de extrema importância uma vez que a difusão do conhecimento adquirido na graduação para a comunidade escolar gera impactos muito positivos na vida 
A educação ambiental em ambiente escolar através da prática de vermicompostagem como forma de tratamento para os resíduos sólidos orgânicos

CERQUEIRA, V. S.; ADAMOLI, H. J.; SILVA, C. F. L.; PEDRA JUNIOR, M. F.

dos alunos levando não somente conhecimentos, mas despertando a consciência ambiental. Em um trabalho desenvolvido por Rodrigues et al. (2010), quando perguntado a alunos da 6a , 7ạ e 8a série, onde 80 alunos responderam ao questionário, $60 \%$ deles responderam que separam os resíduos em suas residências e outros 14\% não separam. Já no trabalho realizado por Klippel (2015), onde 100 alunos responderam ao questionário sendo $50 \%$ de alunos do 5 o ano e $50 \%$ de alunos do 2 o ano, 57 responderam que costumam separar os resíduos em casa e 43 alunos não.

Foi perguntado aos alunos se eles saberiam dizer o que é reciclagem. Dentre as respostas obteve-se: 'são objetos já usados que com eles você pode fazer outros objetos', 'é colocar em uma lixeira para virar uma coisa nova' e também 'é um meio de proteger o meio ambiente'. No trabalho realizado por Kolbe (2015) em duas escolas, quando perguntado aos alunos o que consideravam mais importante em termos de opções de gestão de resíduos, os alunos de ambas escolas consideraram a reciclagem como mais importante, informando que reciclavam, quando possível, papel, vidro e latas, o que é de grande importância, mas como evidenciado pelo autor, os alunos não consideraram a redução de resíduos como sendo a prioridade.

Também foi solicitado aos alunos da escola que citassem pelo menos quatro resíduos gerados nas suas residências que podem ser reaproveitados ou reciclados. A maioria dos alunos respondeu que eram plásticos, seguidos de papéis/metais, vidros, entre outros. Em trabalho desenvolvido por Rodrigues et al. (2010), os alunos indicaram em maior quantidade a categoria papel como reciclável. Já no trabalho desenvolvido por Felix (2007), quando perguntado às famílias e aos alunos da 4ạ série de uma escola municipal, qual seria a composição dos resíduos gerados em seus domicílios, a resposta foi primeiramente outros, dos quais se encaixavam as pilhas e baterias, seguido de papéis, vidros e orgânicos, plásticos, entre outros. No trabalho desenvolvido por Almeida (2018) em cinco instituições de ensino, os resíduos mais comumente gerados nas escolas se assemelham a alguns dos resíduos mais gerados nas residências dos alunos do atual trabalho, dentre eles plásticos e papéis.

Conforme observa-se na Figura 6, a maioria dos alunos respondeu saber o que é coleta seletiva, fato que pode estar relacionado ao fato de que os alunos citaram que já tiveram contato com a educação ambiental em disciplinas de geografia e ciências na escola, sendo provavelmente já anteriormente comentado com eles sobre este assunto.

A coleta seletiva tem um grande destaque no que se refere à reciclagem e reutilização, assim foi dado ênfase sobre esse instrumento da PNRS. No município de Pelotas, há a modalidade de coleta seletiva que tem como principal objetivo o recolhimento de materiais recicláveis e/ou passíveis de reutilização. Os resíduos são coletados por caminhões em dias e horários específicos e encaminhados às Cooperativas de Catadores no município. Já os resíduos orgânicos juntamente com os rejeitos são coletados pela coleta convencional e destinados para o aterro sanitário localizado no município de Candiota/RS, distante 154 Km de Pelotas.

Atualmente o município também tem 05 (cinco) ecopontos, distribuídos em diferentes bairros, que recebem materiais recicláveis, como plásticos de origem domiciliar, papelão, vidros e metais, além de móveis 
A educação ambiental em ambiente escolar através da prática de vermicompostagem como forma de tratamento para os resíduos sólidos orgânicos

CERQUEIRA, V. S.; ADAMOLI, H. J.; SILVA, C. F. L.; PEDRA JUNIOR, M. F.

desmontados, restos de podas e jardinagem, e resíduos de construção civil: aterro, argamassa, concreto e tijolos. O primeiro ecoponto foi instalado no ano de 2016 na região central da cidade. Entretanto, na região onde está instalada a escola onde o projeto foi desenvolvido é bastante frequente o fato das pessoas descartarem resíduos de móveis nas calçadas e em terrenos baldios, o que é uma atitude completamente errada. Os descartes incorretos podem ocorrer devido aos moradores da região não terem o conhecimento de que a cidade conta com ecopontos.

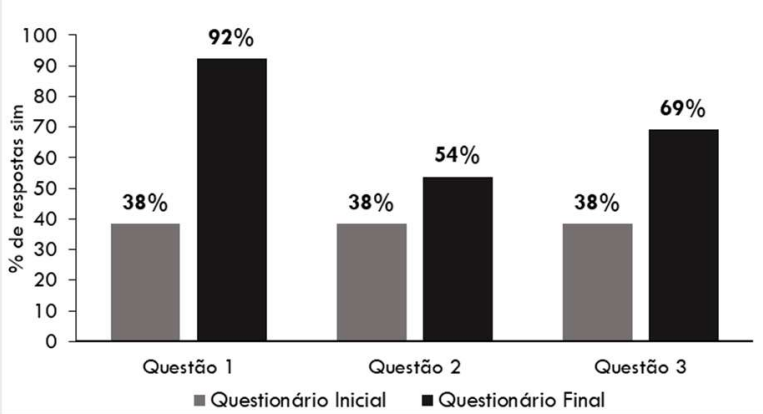

Figura 5: Quantidade de respostas sim (\%) para as questões 1, 2 e 3. Questão 1: Você sabe o que é resíduo? Questão 2: Você faz a separação dos resíduos na sua casa? Questão 3: Você sabe qual a importância da separação dos resíduos?

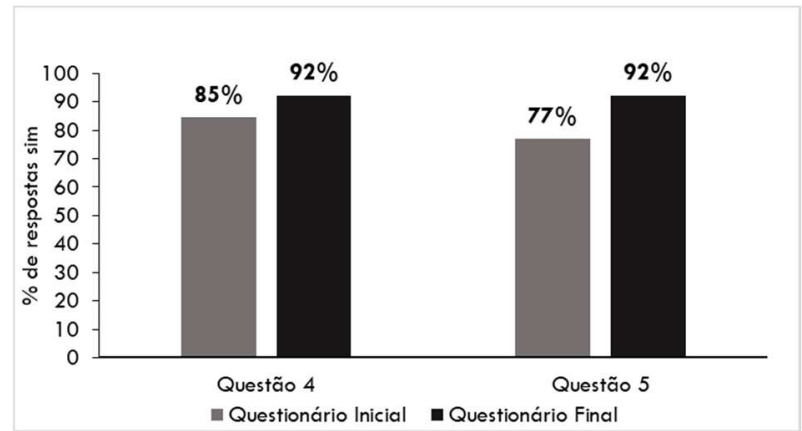

Figura 6: Respostas sim (\%) para as questões 4 e 5. Questão 4: Você sabe o que é coleta seletiva? Questão 5: Já foi abordado a educação ambiental na escola?

Em vista do exposto, ações de EA em escolas mostram-se extremamente necessárias, a exemplo desta desenvolvida no projeto. Em trabalho desenvolvido por Alencar et al. (2020), foi verificado que os professores de escolas públicas no município de Jaramataia/AL, Brasil, reconhecem que é de fundamental importância trabalhar a educação ambiental em sala de aula junto aos alunos, entretanto esta temática além de estar restrita a conservação do meio ambiente e conscientização, é comprometida por diversas dificuldades onde os professores não se sentem preparados para trabalhar essa temática. Assim, os professores acreditam que essa temática deveria ser trabalhada, sobretudo, na forma de 'projetos', o que despertaria maior interesse dos alunos, possibilitando maior contato com a parte prática (Alencar et al., 2020). Sukma et al. (2020), a partir de questionário aplicado a professores, evidenciaram que a maioria dos docentes acham importante integrar a EA no processo de aprendizagem, especialmente dos alunos do ensino fundamental, entretanto, há algumas dificuldades nesta inserção como por exemplo tempo insuficiente. Também foi verificado que dentre os tópicos que poderiam ser inseridos no processo de aprendizagem o que obteve maior número de resposta foi gerenciamento de resíduos sólidos (93\%) (SUKMA et al., 2020).

A EA tem como objetivo levar a consciência de que devemos cuidar do meio ambiente, por meio do nosso pensamento e de nossas atitudes cotidianas. Assim, esse instrumento da PNRS tem em vista sensibilizar as crianças de hoje a ter um meio ambiente equilibrado através de práticas sustentáveis.

A EA desenvolvida nas escolas é importante, pois ensina os alunos sobre as questões envolvendo o meio ambiente, de forma a contribuir com a construção de aprendizado dos alunos, de modo que faça com que eles desenvolvam atitudes sustentáveis. A EA é fundamental em todos os graus de ensino da educação, mas principalmente em anos iniciais, pois as crianças irão repassar o que aprenderam para outras pessoas 
do seu convívio, como a família e a comunidade (RODRIGUES et al., 2010; MEDEIROS et al., 2011). Quanto maior o número de pessoas com conhecimento a respeito do descarte correto dos resíduos, mais se evita problemas, pois os resíduos que não são administrados de maneira correta, acabam sendo um risco preocupante para a saúde (ALAM et al., 2013).

Quando perguntado aos alunos se eles saberiam para que servia a compostagem, observou-se que no questionário inicial nenhum aluno sabia ou não respondeu. Já no questionário final, os alunos deram respostas como: 'para fazer adubo para as plantas', 'para húmus' e 'para a horta', o que demonstra um ponto muito positivo sobre as atividades que foram desenvolvidas com os alunos no projeto.

Os alunos aprenderam sobre a técnica de vermicompostagem e o seu processo de montagem, conforme foi perguntado no questionário. Do total de alunos, destaca-se que a maioria respondeu que saberia fazer uma composteira em casa (Figura 7), o que é um ponto muito positivo, pois assim, percebe-se que após as explicações tanto teóricas quanto práticas, os alunos assimilaram o que os graduandos ensinaram a eles.

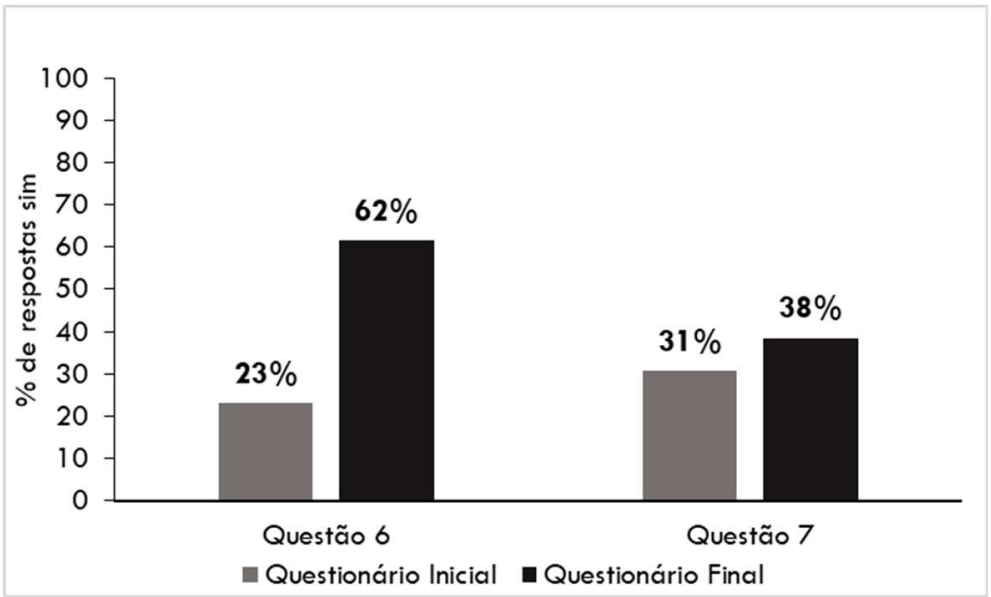

Figura 7: Respostas sim (\%) para as questões 6 e 7. Questão 6: Você saberia fazer uma composteira em casa? Questão 7: Você tem horta em casa?

Do total de alunos, $38 \%$ responderam possuir horta em casa. Provavelmente um aluno se confundiu na hora de responder, pois no questionário inicial 31\% possuíam horta e no questionário final este número mudou para $38 \%$. O entendimento sobre a técnica de vermicompostagem possibilita a sua implementação e consequente uso do vermicomposto produzido para uso nas suas hortas, minimizando custos com a aquisição de adubo comercial e minimizando impactos ambientais.

Por fim, foi perguntado qual solução os alunos dariam para o resíduo orgânico gerado em suas casas. No questionário inicial a maioria não soube responder. Entretanto, no questionário final, obteve-se respostas, como: 'fazer adubo para pôr nas árvores', 'colocar no minhocário', 'fazer composteira', entre outras, mostrando que eles compreenderam sobre formas sustentáveis de tratamento aos resíduos sólidos orgânicos e interesse em dar o destino correto aos resíduos.

A PNRS incentiva a implantação de sistemas de compostagem para resíduos sólidos orgânicos e utilização do composto produzido, entretanto no município de Pelotas ainda não há tratamento para estes resíduos, sendo enviados para aterro sanitário. Praticar a técnica de vermicompostagem nas residências e 
A educação ambiental em ambiente escolar através da prática de vermicompostagem como forma de tratamento para os resíduos sólidos orgânicos

CERQUEIRA, V. S.; ADAMOLI, H. J.; SILVA, C. F. L.; PEDRA JUNIOR, M. F.

em escolas, está em consonância com a PNRS, evidenciando a importância do ensino desta técnica e da difusão de conhecimentos de resíduos sólidos através da educação ambiental em escolas de ensino fundamental.

\section{CONCLUSÕES}

Com as práticas de Educação Ambiental desenvolvidas na escola para os alunos do 60 ano, foi possível transmitir conhecimentos sobre as formas corretas de gerenciamento dos resíduos sólidos, dando ênfase a forma sustentável de tratamento dos resíduos orgânicos através da prática de vermicompostagem.

Os resultados obtidos foram satisfatórios haja visto que os alunos mostraram conhecimento, entusiasmo e interesse em adotar as práticas ambientais. O projeto desenvolvido é de extrema importância no processo de aprendizagem dos alunos, pois estes irão se tornar cidadãos mais conscientes em relação às questões ambientais possibilitando que atuem como multiplicadores do conhecimento adquirido na escola a outras pessoas.

AGRADECIMENTOS: Agradecemos à Escola Municipal de Ensino fundamental pela oportunidade de realização do projeto e à Pró-Reitoria de Extensão e Cultura (PREC) da Universidade Federal de Pelotas pela concessão da bolsa.

\section{REFERÊNCIAS}

ABRELPE. Associação Brasileira de Empresas de Limpeza Pública e Resíduos Especiais. Panorama dos resíduos sólidos no Brasil 2020. São Paulo: ABRELPE, 2020.

ALAM, P.; AHMADE, K.. Impact of Solid Waste on Health and the Environment. International Journal of Sustainable Development and Green Economics (IJSDGE), v.2, p.165168, 2013.

ALCÂNTARA, M. C. O.; VANI, G. S.; ALMEIDA, A. A. S.; SUDA, C. N. K.. Compostagem e educação ambiental: visão da comunidade escolar avaliada pelo método da análise de conteúdo. Ambiente \& Água - An Interdisciplinary Journal of Applied Science, Taubaté, v.11, p.1136-1148, 2016. DOI: http://dx.doi.org/10.4136/ambi-agua.1901

ALENCAR, V. E. M.; SILVA, R. N.. Educação ambiental na percepção de professores de escolas públicas, localizadas em Jaramataia/AL, Brasil. Diversitas Journal, Santana do Ipanema, v.5, n.3, p.1658-1670, 2020. DOI: https://doi.org/10.17648/diveristas-journal-v5i3-854

ALMEIDA, J. A.. Gestão de resíduos sólidos em instituições de ensino: experiências internacionais, nacionais e no município de Belo Jardim/PE. Revista Gestão \& Sustentabilidade Ambiental, Florianópolis, v.7, n.1, p.467485, 2018. DOI:

http://dx.doi.org/10.19177/rgsa.v7e12018467-485

AQUINO, A. M.; OLIVEIRA, A. M. G.; LOUREIRO, D. C.. Integrando Compostagem e Vermicompostagem na Reciclagem de Resíduos Orgânicos Domésticos. Seropédica:
Circular Técnica - Embrapa, 2005.

ARNALDO, M. A.; SANTANA, L. C.. Políticas públicas de educação ambiental e processos de mediação em escolas de Ensino Fundamental. Revista Ciência \& Educação, Bauru, v.24, n.3, p.599-619, 2018. DOI: https://doi.org/10.1590/1516-731320180030005

AYILARA, M. S.; OLANREWAJU, O. S.; BABALOLA, O. O.; ODEYEMI, O.. Waste Management through Composting: Challenges and Potentials. Sustainability, v.12, n.11, 4456, p.1-23, 2020. DOI: https://doi.org/10.3390/su12114456

BRASIL. Lei n.12305 de 2 de agosto de 2010. Institui a Política Nacional de Resíduos Sólidos; altera a Lei no 9.605, de 12 de fevereiro de 1998; e dá outras providências. Brasília: DOU, 2010.

BRASIL. Resolução CONAMA n.275: Estabelece o código de cores para os diferentes tipos de resíduos, a ser adotado na identificação de coletores e transportadores, bem como nas campanhas informativas para a coleta seletiva. Brasília: DOU, 2001.

CEMBRANEL, A. S.; FRANCISCHETT, M. N.; RODRIGUES, C. R.. Educação ambiental com estudantes e famílias na gestão dos resíduos sólidos urbanos. Revista Brasileira de Educação Ambiental, São Paulo, v.14, n.1, p.171-185, 2019. DOI: https://doi.org/10.34024/revbea.2019.v14.2594

FELIX, R. A. Z.. Coleta seletiva em ambiente escolar. Revista Eletrônica do Mestrado em Educação Ambiental, Rio 
A educação ambiental em ambiente escolar através da prática de vermicompostagem como forma de tratamento para os resíduos sólidos orgânicos

CERQUEIRA, V. S.; ADAMOLI, H. J.; SILVA, C. F. L.; PEDRA JUNIOR, M. F.

Grande, v.18, p.56-71, 2007.

IQBAL, A.; LIU, X.; CHEN, G. H.. Municipal solid waste: Review of best practices in application of life cycle assessment and sustainable management techniques. Science of the Total Environment, v.729, p.1-12, 2020. DOI: https://doi.org/10.1016/j.scitotenv.2020.138622

JACOBI, P. R.; BESEN, G. R.. Gestão de resíduos sólidos em São Paulo: desafios da sustentabilidade. Revista Estudos Avançados, São Paulo, v.25, n.71, p.135-158, 2011. DOI: https://doi.org/10.1590/S0103-40142011000100010

KAZA, S.; YAO, L.; BHADA-TATA, P.; WOERDEN, F. V.. What a Waste 2.0: A Global Snapshot of Solid Waste Management to 2050. Urban Development Series. Washington: World Bank, 2018. DOI: http://dx.doi.org/10.1596/978-1-4648$\underline{1329-0}$

KLIPPEL, A. S.. Gerenciamento de resíduos sólidos em escolas públicas. Monografia (Especialização em Gestão Ambiental em Municípios) - Universidade Tecnológica Federal do Paraná, Medianeira, 2015.

KOLBE, K. D.. Knowledge, Attitudes and Behaviour regarding Waste Management in a Grammar and a Comprehensive School in England - Results from a School Questionnaire. Journal of Teacher Education for Sustainability, v.17, n.1, p.58-71, 2015. DOI: https://doi.org/10.1515/jtes-2015-0005

LIAO, C.; LI, H.. Environmental education, knowledge, and high school students' intention toward separation of solid waste on Campus. International Journal of Environmental Research and Public Health, v.16, n.9,p.1-15, 2019. DOI: https://doi.org/10.3390/ijerph16091659

LOUREIRO, D. C.; AQUINO, A. M.; ZONTA, E.; LIMA, E.. Compostagem e vermicompostagem de resíduos domiciliares com esterco bovino para a produção de insumo orgânico. Pesquisa Agropecuária Brasileira, Brasília, v.42, n.7, p.1043-1048, 2007.

MARQUES, R.; XAVIER, C. R.. Análise da aplicação de um recurso educacional sobre a pegada ecológica do lixo na educação ambiental. Revista Educação Ambiental em Ação, v.16, n.63, 2018.

MEDEIROS, A. B.; MENDONÇA, M. J. S. L.; SOUSA, G. L.;
OLIVEIRA, I. P.. A importância da educação ambiental na escola nas séries iniciais. Revista Faculdade Montes Belos, v.4, n.1, p.1-17, 2011.

MENDONÇA, R. S. A.; ALMEIDA, J. P.. A educação ambiental no ensino de Geografia nas escolas urbanas do município de Japaratinga/AL. Diversitas Journal, Santana do Ipanema, v.5, n.2, p.1080-1099, 2020. DOI:

https://doi.org/10.17648/diversitas-journal-v5i2-1146

PATHMA, J.; SAKTHIVEL, N.. Microbial diversity of vermicompost bacteria that exhibit useful agricultural traits and waste management potential. Springer Plus, v.1, n.26, p.1-19, 2012. DOI: https://doi.org/10.1186/2193-1801-1-26

RADA, E. C.; BRESCIANI, C.; GIRELLI, E.; RAGAZZI, M.; SCHIAVON, M.; TORRETTA, V.. Analysis and Measures to Improve Waste Management in Schools. Sustainability, v.8, n.9, p1-12, 2016. DOI: https://doi.org/10.3390/su8090840

RODRIGUES, S.; SILVEIRA, A. S. B.; PORTELA, I. P.; LEÃO, A. L. S.. Projeto de educação ambiental no contexto escolar. Revista Conhecimento Online, Novo Hamburgo, v.2, n.2, p.161-168, 2010. DOI:

https://doi.org/10.25112/rco.v2i0.153

SO, W. W. M.; CHOW, S. C. F.. Environmental education in primary schools: a case study with plastic resources and recycling. Education 3-13, v.47, n.6, p.652-663, 2019. DOI: https://doi.org/10.1080/03004279.2018.1518336

SUKMA, E.; RAMADHAN, S.; INDRIYANI, V.. Integration of environmental education in elementary schools. Journal of Physics: Conference Series, v.1481, p.1-6, 2020. DOI: https://doi.org/10.1088/1742-6596/1481/1/012136

WANI, K. A.; MAMTA; RAO, R. J.. Bioconversion of garden waste, kitchen waste and cow dung into value-added products using earthworm Eisenia fetida. Saudi Journal of Biological Sciences, v.20, n.2, p.149-154, 2013. DOI: http://dx.doi.org/10.1016/j.sjbs.2013.01.001

ZAGO, V. C. P.; BARROS, R. T. V.. Gestão dos resíduos sólidos orgânicos urbanos no Brasil: do ordenamento jurídico à realidade. Engenharia Sanitária e Ambiental, Rio de Janeiro, v. 24 n.2, p.219-228, 2019. DOI: http://dx.doi.org/10.1590/s1413-41522019181376

A CBPC - Companhia Brasileira de Produção Científica (CNPJ: 11.221.422/0001-03) detém os direitos materiais desta publicação. Os direitos referem-se à publicação do trabalho em qualquer parte do mundo, incluindo os direitos às renovações, expansões e disseminações da contribuição, bem como outros direitos subsidiários. Todos os trabalhos publicados eletronicamente poderão posteriormente ser publicados em coletâneas impressas sob coordenação da Sustenere Publishing, da Companhia Brasileira de Produção Científica e seus parceiros autorizados. Os (as) autores (as) preservam os direitos autorais, mas não têm permissão para a publicação da contribuição em outro meio, impresso ou digital, em português ou em tradução. 